\title{
Gene Therapy Agent
}

National Cancer Institute

\section{Source}

National Cancer Institute. Gene Therapy Agent. NCI Thesaurus. Code C1962.

DNA constructs or co-administered agents used in gene therapy. Gene therapy constructs are used in delivery of genetic material into cells in order to permanently correct an inherited disease or an acquired disease such as cancer. 